\title{
La violencia de género en el distrito de Huancayo Estudio de casos
}

\section{Gender violence in Huancayo district Study of cases}

\author{
'Arredondo Baquerizo, F.L.; ${ }^{2}$ Romero Sihuay, C.A. \\ Facultad de Antropología, Universidad Nacional del Centro del Perú \\ Email: arredondo.fl@gmail.com
}

\section{Resumen}

La investigación tuvo como objetivo general, interpretar los elementos sociales y culturales que constituyen la violencia de género en la ciudad de Huancayo. El enfoque de la investigación fue de tipo cualitativo, nivel descriptivo, muestra no probabilística y método hermenéutico, a través de entrevistas y la interpretación de los testimonios. Se encuestó a 15 mujeres que han sido víctimas de violencia de género. Los datos obtenidos se interpretaron en relación con las teorías de género y violencia de género que existen acerca del tema.

Los resultados muestran que la violencia de género tiene como causa la pérdida de control del cuerpo y de la sexualidad de las mujeres por parte de sus parejas. Los aspectos sociales que se hallaron son: existe un historial de violencia en las víctimas, el trabajo público y remunerado que realizan las mujeres les permiten salir del espacio doméstico lo que genera agresión de parte de las parejas.

La violencia se presenta en todas las etapas de la relación entre hombres y mujeres, los hombres quieren tener dominio en ámbitos privados, quieren que sus parejas hagan las cosas como ellos lo desean; los hombres al no querer "perder" a su pareja, optan por recurrir a pedir perdón y a arrepentirse de su comportamiento.

Palabras clave: violencia de género, sexualidad, cuerpo, machismo

\section{Abstract}

The general objective of the research was interpreting the social and cultural elements that constitute gender violence in the city of Huancayo. The focus of the research was qualitative, descriptive level, non-probabilistic sample and hermeneutical method; through interviews and interpretation of testimonies. Fifteen (15) women who have been victims of gender violence were surveyed. The obtained data was interpreted in relation to of gender and gender violence theories existing on the subject.

Results show that gender violence is caused by the loss of control of the body and the sexuality of women by their partners. Found social aspects are: there is a history of violence in the victims, the public and paid women works allow them to leave the domestic space which generates aggression on the part of couples.

Violence occurs in all stages of men and women relationships , men want to dominate in private areas, they want their partners doing things as they wish, men not wanting to"lose" their partner, choose to ask forgiveness and repent of their behavior.

Keywords: gender violence, sexuality, body, machismo 


\section{Introducción}

Uno de los temas de mayor preocupación dentro de las políticas del Estado peruano actual, es la violencia de género y la violencia contra la mujer; este interés, se expresa a través de las políticas del Ministerio de la Mujer y de Poblaciones Vulnerables (MIMP) y de otros organismos estatales, mediante la implementación de leyes especiales y más drásticas para estos casos. Incluso el MIMP, ha implementado en todos los distritos del país Centros de Emergencia Mujer (CEM) y, últimamente, ha implementado el Programa Nacional Contra la Violencia Familiar y Sexual (PNCVFS), que tienen como objetivos optimizar la atención para personas víctimas de violencia familiar y prevenir la violencia sexual. Este nuevo programa (su implementación empezó en junio 2017 en todo el país), tiene una atención diaria, incluso sábados, domingos y feriados y el horario de atención son las 24 horas del día y, está integrado por un equipo multidisciplinario de profesionales. Estas y otras medidas refleja la importancia que tiene este problema.

Por su parte, la sociedad civil también ha manifestado su preocupación mediante algunas ONGs y colectivos feministas realizan talleres, elaboran proyectos, campañas y marchas en las calles de diferentes ciudades del país, mostrando su preocupación por la violencia contra la mujer e intentando sensibilizar a la población civil.

El sector académico no es ajeno a estos hechos, en realidad el tema de la violencia de género y de la violencia contra la mujer, son contenidos de los Estudios de Género que se iniciaron en la década de los setenta del siglo veinte; sin embargo, estos estudios no son acabados, constantemente se van renovando y profundizando con las investigaciones porque en las ciencias sociales no hay nada definitivo ni finiquitado, en ese sentido, algunas investigaciones van incrementando y aclarando ciertas categorías que se utilizan en este problema.

Existen debates sobre la violencia de género desde muchas perspectivas y disciplinas científicas; como la psicología, la antropología, la sociología, el derecho y otros. Algunas de ellas reducen este tipo de violencia a la celopatía, otras como la antropología buscan causas sociales y culturales, como la pérdida del control del cuerpo y de la sexualidad femenina como consecuencia de la profesionalización y la inserción de la mujer en el mercado de trabajo.

En ese sentido existen otros aspectos que merecen ser investigados; es violencia contra la mujer o violencia familiar, en qué ámbitos se realiza, públicos o privados, y si la agresora es la mujer, qué pasa en las parejas homosexuales, la violencia es innata o aprendida en el ser humano, qué sucede con los otros integrantes de la familia, si esta violencia se presenta en todos los niveles económicos o es exclusivo de algunos sectores, ¿cuáles pueden ser los motivos que ocasionen que una persona agreda a su pareja, hasta que le quite la vida o la lesione gravemente? ¿qué sucede si este tipo de violencia ocurre en la ciudad, en un barrio marginal o en un distrito rural, donde no existen los centros de atención adecuados y las leyes promulgadas por el Estado son suficientes para detener este hecho?.

Por el lado cultural, se puede investigar los posiciones de las partes en este problema; la víctima, quien percibe esta agresión, lo ha naturalizado, acepta la visión del opresor, hay que recordar que hasta hace poco existía un dicho popular que se tomaba en son de burla "más me pegas y más te quiero" o canciones como "tú eres mi propiedad privada", "sácame la vuelta pero no me dejes" reproducido sobre todo en espacios tradicionales, sería necesario saber si aún persiste esta idea.

Incluso se debe conocer las motivaciones para que una mujer no denuncie a su pareja agresora; puede ser el tema de los hijos, la tradición, la vergüenza, la mala percepción de la justicia en el país, razones subjetivas y, por otro lado, la mujer que denuncia como maneja su entorno familiar, existirá en ella algún remordimiento o sentimiento de culpa. Como se aprecia, el tema es sumamente controvertido y complejo, a través de esta investigación se hizo una mirada a las principales características sociales y culturales que integran este tipo de violencia con el estudio de casos. La interrogante general que se planteó fue: ¿Qué características culturales y sociales presenta la violencia de género en el distrito de Huancayo?

\section{Materiales y métodos}

Se utilizó materiales de acopio de información, sobre todo la guía de entrevista, a través de la cual se obtuvo los testimonios de las personas involucradas en la violencia de género, cuaderno de campo. El enfoque que se utilizó en la presente investigación fue el tipo cualitativo, nivel descriptivo, muestra no probabilística para la obtención de los datos y el método hermenéutico para la interpretación de los testimonios de los informantes, contrastando con la teoría de género y la teoría de violencia de género.

\section{Resultados}

A continuación la guía de preguntas y la interpretación de los testimonios de los casos:

\section{¿Desde cuándo ha ejercido violencia su pareja contra Ud.?}

Los testimonios refieren un historial de violencia desde la etapa de enamoramiento, no es instantáneo, el hombre espera tener una poco de confianza con la pareja, y luego empiezan las agresiones, primeros verbales - psicológicas, hasta las físicas, esto acompañado con la posesión y el control de los comportamientos de la señora o señorita. 


\section{¿Podría detallar la forma en que su esposo es vio- lento o agresivo con $U d$ ?}

Las agresiones halladas en la investigación son principalmente: psicológicas y físicas; las primeras son humillaciones e insultos dirigidas hacia las formas como realizan las labores domésticas la mujer, "no sabes hacer nada", o "todo lo haces mal", las segundas dirigidas a la sexualidad de la mujer y a su pasado sexual; además, involucra a la familia de la mujer.

\section{¿Cuál o cuáles son los motivos del comportamiento violento de su pareja y de las peleas? \\ Los motivos son la pérdida de control del hombre res- pecto a su pareja, cuando la mujer sale a los espacios pú- blicos a trabajar o simplemente cuando el hombre siente que su pareja se tarda mucho en la calle, como en visi- tar a sus familiares. Cuando la mujer reclama al esposo por alguna infidelidad, el hombre, en contraposición, no quiere ser controlado.}

¿Cuál ha sido la experiencia más violenta que ha sufrido?

Las experiencias más violentas que han sufrido las mujeres son los golpes que las han dejado postradas e inválidas temporalmente para realizar sus actividades cotidianas. Estas circunstancias se presentan asociadas a la infidelidad masculina y a la insuficiencia de recursos económicos en la familia, y va acompañada de insultos, a destrucción de algunas cosas del hogar.

\section{¿Cómo afecta la violencia de su pareja a la familia?}

Afecta a los hijos, ellos sienten el terror de la violencia entre sus padres, según los testimonios de la madre, sus hijos se quedan paralizados o se ocultan ante este hecho, cuando los hijos son mayores toman partido por la madre, si es hijo incluso puede llegarse a enfrentar al padre, la madre no quiere que su hogar quede dividido, no desea que sus hijos lleguen a odiar al padre. La mujer oculta este hecho a su propia familia con el objetivo de que el problema se desborde, a veces se queja a la familia de la pareja sin obtener un apoyo real, en algunos casos incluso la acusan de haber realizado algún "acto indebido" que provocó la reacción violenta del hombre.

\section{¿Ud. ha perdonado u olvidado el comportamiento violento de su esposo / pareja?}

El hombre pide perdón a su pareja por su comportamiento violento, prometiendo que lo ocurrido no volverá a suceder; sin embargo, pasa algún tiempo y el comportamiento se vuelve a repetir. Esta actitud de pedir perdón, es una estrategia del hombre al pensar que su esposa lo puede denunciar o peor aún dejar por su comportamiento. Por otro lado, algunas mujeres perdonan porque según ellas no tienen otra alternativa, total tiene que quedarse con su pareja, haciendo un sacrificio por su familia y por sus hijos.

\section{¿Ha denunciado a su esposo o pareja por su com-} portamiento violento?

Las mujeres más jóvenes han ido a denunciar a sus parejas por su comportamiento, han ido al puesto policial o al Centro de Emergencia Mujer de Huancayo para que les oriente en su denuncia; sin embargo, las que denuncian no continúan con los trámites, abandonan a medio camino, no pasan la revisión del médico legista y no llegan a formalizar la denuncia. Los motivos, para no denunciar o no continuar la denuncia, son la desconfianza en la justicia peruana y el temor a quedar desamparadas económicamente la familia y ellas mismas.

\section{¿Se ha separado o pensado separarse por el maltrato que sufre?}

La mayor parte no se ha separado definitivamente, algunas si lo han hecho temporalmente por algunas semanas, hasta que ellas mismas, por voluntad propia han regresado, otras porque sus parejas les han buscado, aunque previamente han pedido perdón. Las señoras no quieren que sus hogares se rompan, ellas asumen que su vida sentimental ya está definida con sus parejas, no creen que puedan empezar solas nuevamente, también ponen como explicación que este sacrificio lo hacen por sus hijos.

Figura 1

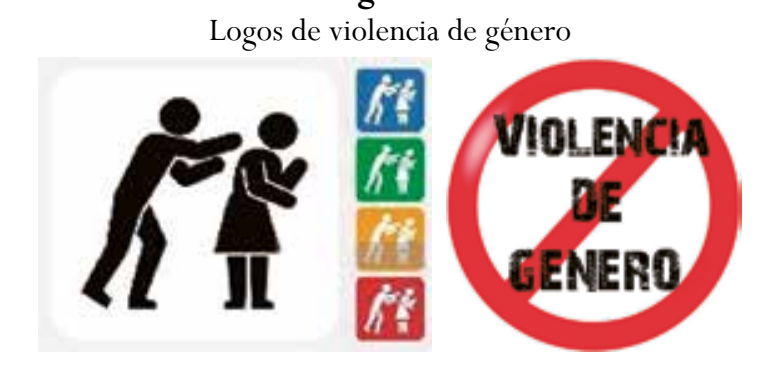

\section{Discusión}

\section{Temporalidad de la violencia}

La violencia que ejercen los hombres sobre sus parejas, tiene un historial que empieza en la etapa de enamoramiento y luego, a través de los años, va tomando mayores dimensiones; empiezan con gritos, insultos y humillaciones, la mujer no le da mucha importancia piensa que son aspectos temporales de la relación, ella cree que no reviste gravedad, que es algo "normal" dentro de las parejas y por eso no se preocupan de ponerle un límite o fin a la relación con sus parejas.

En la etapa del noviazgo, el hombre se "siente" con mayores derechos para reclamar a su pareja sobre su forma de vestir, sobre con quién hace amistad, sobre las salidas de las jóvenes, pero este reclamo se traduce ya no solo en gritos, humillaciones, sino en golpes, con mayor frecuencia; cachetadas, puñetes y patadas, las mujeres en esta instancia manifiestan dos elementos; ellas piensan que sus parejas pueden cambiar por los arrepentimientos 
que éstos muestran (piden perdón) y no se sienten con el suficiente valor para terminar la relación, pues, ya están “varios años" con ellos y hay una costumbre.

Al respecto Cuervo y Martínez (2013), desde una perspectiva psicológica indican que existe un ciclo de violencia para el caso colombiano, donde los autores identifican tres fases; primera, compuesta por violencia verbal, psicológica y económica; la segunda, violencia física y/o sexual y; la tercera, reconciliación promesas por parte del agresor de cambiar.

Walker (1979), reconoce tres fases, para el caso norteamericano; en la primera, se habla mal de la pareja, comentarios intimidantes, mezquindad, maltrato físico leve, empujones, el agresor manifiesta hostilidad e insatisfacción, la mujer intenta calmar al agresor y la mujer evita agravar la situación; la segunda fase, hay una descarga incontrolable de tensiones que se han acumulado en la primera fase, el agresor ataca verbalmente y físicamente a la víctima, a menudo la deja herida, en esta fase la mujer se defiende pudiendo herir o incluso matar a su agresor, dos tercios de los agresores realizan estos actos alcoholizados y; en la tercera fase, el agresor presenta sus disculpas, remordimientos y entrega a la víctima regalos y promesas, la víctima cree que su relación tiene salvación y que la violencia no volverá a ocurrir. El agresor se muestra amable y la víctima cree que la violencia ha pasado. En este ciclo se repite la violencia, la cual se vuelve más peligrosa, el agresor aprende a manipular a su víctima y sabe que no necesita mucho esfuerzo para obtener el perdón de su pareja.

Contrastando con los casos investigados, se percibe un ciclo que se inicia desde la etapa del enamoramiento donde se empieza a manifestar algunos aspectos de control del hombre sobre el cuerpo de la mujer; lo que si se repite, es la fase de arrepentimiento y las disculpas, a lo que accede la mujer fácilmente pensando que el agresor cambiará.

\section{Formas de la violencia de género}

Se nota dos formas principales de violencia: la psicológica y la física; la primera, se manifiesta mediante gritos, humillaciones en forma de gritos, insultos que no solo involucra a la mujer, sino a la familia de la mujer y hasta a los hijos, se prefiere hablar sobre la vida sexual de la mujer, peor aún si ella ha tenido alguna pareja o parejas anteriormente, entonces se le enrostra que ha tenido una vida sexual activa y, por lo tanto, es una cualquiera, con palabras como puta, perra, ramera, son las preferidas en ser utilizadas por los hombres. Otra forma de humillación, es cuando se le dice a la mujer que es una inútil, que no sirve para nada, no sabe cocinar, no sabe hacer las labores de la casa, no atiende bien a los hijos, se le responsabiliza de todo lo que sucede en el hogar, al hombre le gusta comparar con su mamá, mientras que la esposa es incapaz de todo, la mamá es el modelo que ella debe seguir. También se hace referencia a la incapacidad de criar a los hijos, cuidar al esposo e incluso no ser capaz de "ser mujer".

Dentro de la violencia física, lo ya mencionado; cachetadas, puñetes, patadas, jalar el cabello, golpes en algunas zonas como en el estómago, la utilización de algunos elementos, palos o algún objeto al alcance de los hombres, esto potencializa el daño que puedan sufrir la mujeres, a algunas las dejan incapacitadas para trabajar y hasta para caminar. Incluso las pueden dañar seriamente u ocasionarles la muerte.

Segato (2003), reconoce la violencia psicológica o moral mostrando preocupación porque es mencionada superficialmente e introducida como complemento de la violencia física y lo considera como un conjunto de mecanismos para mantener una situación dada, es una forma de violencia, más irreflexiva e intimidante. Se caracteriza por ser masiva, naturalizada y difícil de denunciar. En contraste la violencia física es evidente y denunciable porque hay un daño evidente.

Pérez y Hernández (2019), para el caso cubano, sostienen que la violencia psicológica lo considera como abusos, omisiones orientadas a controlar los comportamientos de las mujeres por medio de intimidaciones o amenazas. Se trata de convencer a la víctima que ella es culpable de cualquier problema.

A partir de la teoría propuesta se encuentran coincidencias, la violencia psicológica está orientada a menoscabar la autoestima de la mujer, los insultos van dirigidos tanto a sus labores culturalmente considerados como propios de su género, "no sabe cocinar”, "no es como la mamá de esposo", "no sabe ser mujer"y/o "no cuida bien a los hijos"; pero también, a los roles donde ella ha estado ingresando en las últimas décadas "no es una buena profesional”, "es inútil en el hogar y en el trabajo", "cómo habrá logrado éxito profesional” entre otros. Se intenta que la víctima internalice y naturalice estos insultos a través de la repetición cotidiana.

La interpretación sobre la violencia desde la antropología, teniendo en cuenta la teoría de la identidad, se construye en oposición al otro, alter ego, implica antagonismo, el hombre construye su masculinidad de acuerdo a ciertas características que propone la sociedad y la cultura, como lo señala Ruíz (2001), insensible al dolor, territorial, dominante hacia la mujer e incluso hacia otros hombres, también se señala que la identidad masculina se construye en oposición a ciertas características femeninas, no ser mujer, homosexual, ni niño. En tiempos de crisis de masculinidad, se debe reafirmar esta identidad, las mujeres van consiguiendo ciertas libertades que antes carecía, ante lo cual se reacciona con violencia, el hombre tiene miedo de perder ciertas prerrogativas, humilla, insulta, deshumaniza a su pareja, el paso inmediato es el 
golpe físico que la puede lesionar y hasta matar, a ese otro amenazante que le puede quitar ciertos privilegios que se había acostumbrado a ejercer.

\section{Motivos para la violencia de género}

No es creible que existan motivos para ejercer violencia de una persona sobre otra; sin embargo, en algunas explicaciones que las mismas víctimas brindan, se pudo notar, a través de la investigación, que la principal es el control y dominio de los hombres hacia las mujeres, que otras autoras consideran como el tema de dominio y subordinación, en espacios privados y públicos.

Dentro de lo privado, el hombre siente que debe ser atendido y cuidado por su pareja, de igual modo de los hijos, ella demuestra amor e interés por él, también la señora debe ocuparse de los quehaceres del hogar de una manera prolija y las tareas deben hacerse de acuerdo a las preferencias y gustos del hombre; dentro de este espacio, lo que resalta es el control del cuerpo de la mujer, la mujer si trabaja o si sale a visitar a su familia debe regresar de inmediato al hogar, no debe de tener amigos, ni amigas, el esposo debe controlar las llamadas telefónicas; asimismo, el hombre debe controlar hasta el pensamiento de la esposa "qué estás pensando", "qué estás haciendo".

El dominio masculino hacia las mujeres es histórico, Bourdieu (1990), señalaba que este dominio está bien asegurado como para requerir justificación, esta expresado en refranes, proverbios, enigmas, cantos, poemas, en representaciones gráficas, adornos en los tejidos, cerámica, en la estructura del espacio, divisiones interiores de la casa, oposiciones, en rituales, técnicas del cuerpo, postura, ademanes y porte. El estudio fue realizado por Bourdieu a partir de Kabilia, Grecia y lo extiende a la realidad de Europa occidental.

En el Perú, esta dominación esta entremezclada con el machismo, Ruíz (2001), citando a Norman Palma, menciona que existe una dimensión sádica en la estructura machista, pues el maltrato hacia las mujeres no se produce solo por celos o por rebelión, sino cuando no cumple con las exigencias del hombre, en este caso su pareja. Hay un principio de territorialidad, referido a la posesión del cuerpo de la mujer, que lo considera de su propiedad, frases como "eres mía", "te poseo" o "te hago mía”, son frecuentes cuando se refieren a las relaciones íntimas; además, en el pensamiento machista hay necesidad de aumentar las posesiones y exhibirlas.

De acuerdo con los casos encontrados, y que no considera Norman Palma, también se presenta el caso de violencia causada por la infidelidad del esposo, él no soporta que la esposa le reclame sus faltas en el hogar o que le hayan visto con otra mujer, ante lo cual reacciona con violencia.

\section{La experiencia más violenta}

Se aprecia una ferocidad en los ataques de los hombres a sus parejas, rotura de nariz, patadas en el vientre, puñetes en la cara, en los ojos, apalear y/o dejar en un estado de semi inconsciencia a la víctima, son algunas características recogidas en los testimonios, aunque varios casos de violencia contra la mujer en la sociedad peruana han terminado en feminicidios. Pero, cuál es la explicación para ejercitar este tipo de violencia contra una mujer.

Los hombres no soportan que en los últimos 50 años se hayan suscitado cambios como el ingreso masivo de las mujeres a las universidades, éstas han logrado profesionalizarse y, por ende, han buscado y han encontrado puestos de trabajo remunerado lo que les ha permitido ingresar a espacios públicos. Trabajos, donde conocen a otras personas, conversan o participan en reuniones (celebraciones, cumpleaños, otros), por lo que ya no permanecen en sus hogares exclusivamente al control del marido, estos hechos no son aceptados culturalmente por el hombre, no están habituados para que su pareja disponga de su tiempo y de sus amistades, lo que significa el menoscabo de su poder y esto se traduce en violencia hacia su pareja.

\section{Efectos de la violencia dentro de la familia}

Se ha distinguido dos tipos de reacciones; en los hijos pequeños menores de 10 años existe temor, angustia, ellos se esconden cuando escuchan o ven al padre pegar a la madre, en cambio en los hijos más jóvenes, de 15 años a más, se nota una indignación, hay un enfrentamiento del hijo con el padre, un reclamo por el maltrato a la madre.

Por parte de la víctima, hay un sentimiento de evitar que su familia se resquebraje, por eso trata de minimizar u ocultar el maltrato de su marido a sus propios hijos, evita que estos se enfrenten al papá o que no le estimen, pero sobre todo a su propia familia, porque teme que su padre, madre o hermanos reclamen los maltratos a su hija. Tomando el conflicto de pareja otras dimensiones que involucran a la familia de ambos. Solo si la situación es extrema la familia de la esposa se entera y allí el problema puede llegar hasta la denuncia policial.

A veces la esposa se queja a la suegra, pero ésta sale a favor de su hijo, responsabilizándola de su propio maltrato.

\section{Perdón por el comportamiento violento del esposo}

Se notó que después de una pelea, el esposo pide perdón a la esposa, con algún regalo, generalmente flores, hasta se arrodilla con el fin de que ella lo perdone, él promete que esta violencia no se repetirá, incluso señala que no estaba en sus cabales cuando reaccionó de esa manera; es decir, trata de justificarse por todos los medios, la esposa lo perdona pensando en la unidad de su familia, pero la agresión vuelve a repetirse después de un tiempo. Cuando las peleas han sido por infidelidad del esposo a la señora, perdona, pero siempre existe recuerdos sobre 
ese hecho, y cuando se evoca este hecho surgen los conflictos nuevamente.

Yugueros (2014), considera a esta fase como "luna de miel”, donde el agresor adopta un rol de bondad y generosidad, arrepentido del mal causado, jura y promete que nunca volverá a suceder el maltrato.

Romero (2010), también reconoce la fase de "luna de miel”, donde el esposo hace promesas de no volver a ser violento, la víctima ve el lado bueno del esposo y perdona. Los autores que reconocen estas fases siguen un pensamiento psicológico inspirado en la antropóloga Leonore Walker; sin embargo, estas fases no son lineales, ni correlativas de acuerdo a la investigación, las personas agredidas señalan que desde un principio, sus parejas pueden ser extremadamente violentas, y el arrepentimiento se puede presentar en cualquier momento, la generosidad si es recurrente, la mujer recuerda los buenos momentos que paso con su pareja, por eso ella piensa que esos momentos románticos pueden volver y acceden a perdonar.

\section{La denuncia a la pareja}

La denuncia de la mujer a su pareja por violencia, conlleva que la mujer tome una decisión sabiendo que este hecho va a tener algunas consecuencias como; la propia familia se va a resquebrajar, la familia de su esposo va a tomar una posición contra la nuera y a favor del hijo, la "vergüenza" antes los amigos y familiares, el miedo a la reacción del esposo, el temor a que el esposo no cumpla con su rol de proveedor en la familia y la incertidumbre ante la justicia que ella pueda alcanzar ante su denuncia. Por estas razones, pocas mujeres se atreven a realizar una denuncia. Ellas solo lo han pensado pero no lo han llevado a cabo a la práctica.

Las mujeres que han denunciado, ha sido con el apoyo y el acompañamiento de su familia o de amigas que las han alentado a sentar la denuncia, lo característico que no terminan el proceso, lo dejan, antes de ir al médico legista para que certifique la gravedad de la lesión.

Un elemento cultural común que las mujeres afrontan cuando concurren a un puesto policial es que el guardia encargado de recibir la denuncia expresa; “Qué habrás hecho?", dando a entender que la responsabilidad y la culpa de la violencia en la casa es la mujer. La mujer debe portarse de acuerdo a ciertas normas culturales para evitar este tipo de situaciones. Se asume que la esposa no atiende bien al esposo o a los hijos, reclama mucho, es descuidada en su hogar, aburre o molesta al marido, entre otros.

\section{Separarse del esposo por la violencia}

Las señoras no se separan de sus esposos por los actos de violencia por los siguientes motivos: tienen miedo de vivir solas, temor a la falta de recursos económicos, pues el esposo es el proveedor de la familia (a pesar que algunas mujeres también trabajan y perciben una remu- neración), evitar el rompimiento de su familia y temor al fracaso familiar y en el amor.

Hay algunas de ellas que se han separado de sus parejas, pero ha sido temporal, algunas semanas o meses, luego han regresado con sus parejas por petición de ellos o por mutuo acuerdo. Otras tienen en sus imaginarios la idea de escapar, irse a algún lugar donde puedan estar solas sin sufrir.

Además, se encontró algunos casos donde la mujer estaba a punto de separarse de su esposo, abandonar el hogar, con sus cosas en una maleta en la puerta de sus casas, pero la pareja no lo permitió de buenas o malas maneras las hizo regresar. El hombre no puede soportar que su pareja la abandone, se repite la norma cultural de controlar el cuerpo y la sexualidad de la mujer.

El aspecto de la denuncia tiene que ser abordada analizando la actuación de los operadores de justicia, en este sentido Parra y Furtado (2016), sobre el caso de Brasil, indican que las mujeres que acceden a denunciar estos hechos teniendo en cuenta muchos factores, incluyendo su evaluación de quienes reciben la denuncia en las comisarías hasta sus concepciones acerca de lo que ellas entienden por violencia, también en la investigación se observa que no existe una continuidad en la denuncia; es decir, la víctima puede abandonar en cualquier etapa el proceso, ellas retiran muchas veces la denuncia, señalando que solo querían dar un escarmiento al agresor, quizás asustarlo. El mérito de la investigación en referencia es haber recopilado numerosas investigaciones sobre el tema; sin embargo, no hay referencia al contexto cultural y social de la víctima y agresor, el tema del machismo y el patriarcado.

\section{Conclusiones}

- La violencia de género, contra la mujer, se presenta en todas las etapas de relación de pareja, en la etapa de enamoramiento, de noviazgo y de matrimonio de hecho o de derecho, las causas que producen esta violencia es el menoscabo del control y posesión del hombre con respecto al cuerpo y a la subjetividad de su pareja.

- La mujer ha ingresado al mercado laboral, producto de su profesionalización, lo que le permite alejarse temporalmente del espacio doméstico e interactuar en el espacio público, participando en actividades económicas y sociales. Ya no está bajo un control directo de la pareja en el hogar, conoce a otras personas, establece relaciones con colegas y participa en actividades propias del trabajo y en otras que no están directamente relacionadas, lo que hace que el hombre vaya perdiendo control sobre su pareja.

- La pérdida de control se manifiesta con violencia; principalmente psicológica, insultos, humillacio- 
nes y física, golpes en el cuerpo femenino que pueden producir graves lesiones o la muerte. Otro elemento que produce la violencia es el hecho que la mujer no realiza sus quehaceres domésticos "de una manera adecuada” de acuerdo a la pareja. La forma que el hombre cree que es la adecuada, es como lo aprendió en su propio hogar tomando como modelo a la propia madre.

- El hombre para no perder a su pareja después de una acción violenta, pide perdón a través de gestos o regalos, la pareja acostumbra a perdonar para que su hogar no se destruya y por presión familiar, hijos, padres y suegros.

\section{Referencias bibliográficas}

Bourdieu, P. (1990). La dominación masculina, $1^{\circ} \mathrm{ed}$. Barcelona, España: Anagrama.

Butler, J. (2017). Deshacer el género. 7ma ed. España: Paidós

Cuervo, M., \& Martínez, J. (2013). Descripción y caracterización del ciclo de violencia que surge en la relación de pareja. Revista Tesis Psicológica, 8 (1), 80-88.

Dador, J. (2011). Violencia de género.1ra ed. Lima, Perú: Ed. Consorcio de investigación económica y social.

Enríquez, N. (2006). Cuestiones de género y poder en el conflicto armado en el Perú. 1 ra ed. Lima, Perú: CONCYTEC.

Espinoza, M. (2001). Violencia en la familia en Lima y el Callao. 2da ed. Lima, Perú: Congreso del Perú.

Fuller, N. (2002). Masculinidades, cambios y permanencias. 1ra ed. Lima, Perú: Pontificia Universidad Católica del Perú.

Gonzáles, (2016). Incumplimiento de las medidas de protección dictadas al amparo del artículo 10 de la Ley de protección frente a la violencia familiar, según los procesos de ejecución de sentencia en violencia familiar del segundo y cuarto juzgado de familia de la corte superior de justicia de Arequipa, de enero del 2010 a diciembre del 2011. (Tesis de maestría) Universidad Católica de Santa María, Arequipa.

Héritier, F. (2007). Masculino/femenino II. Disolver la jerarquía. 1ra ed. México: Fondo de Cultura Económica.

Hernández, R. Fernández, C. y Baptista, P. (2014). Metodología de la investigación. 6ta ed. México: Mac Graw Hill.
Isbell, B. (1976). La otra mitad esencial; un estudio de complementariedad sexual en los Andes. Lima, Perú: Estudios andinos.

Lagarde, M. (2005). Los cautiverios de las mujeres: madresposas, monjas, putas, presas y locas. 4 ta ed. México: Universidad Nacional Autónoma de México.

Lamas, M. (1998). La violencia del sexismo en el mundo de la violencia. 1 ra ed. México: Fondo de Cultura Económica.

Lorente, M. (2001). Mi marido me pega lo normal. Agresión a la mujer: mito y realidades. 1a ed. Barcelona, España: Ares y Mares.

Pérez, V. y Hernández, Y. (2009). La violencia de género, una forma encubierta de agresión. https://www.researchgate.net/publication/237700662_La_violencia_psicologica_de_genero_una_forma_encubierta_de_agresión.

Maqueira, V. (2010). Mujeres, globalización y derechos humanos. 2da ed. Madrid, España: Catedra.

Mujica, J. (2011). Violaciones sexuales en el Perú $2000-$ 2009. Un informe sobre el estado de la situación. 1 ra Ed. Lima, Perú: PROMSEX.

Oblitas, B. (2014). Machismo y violencia contra la mujer. UNMSM Investigaciones Sociales. 13. (23). $301-322$.

Osborne, R. (2009). Apuntes sobre violencia de género. 1ra ed. España: Bellaterra.

Parra, M. y Furtado, A. (2016). Violencia doméstica contra la mujer y el uso de estrategias de afrontamiento: Producción de artículos científicos en Brasil. Revista Psicología desde el Caribe, 33(3), 265-284.

Ramos, M. (2006). Masculinidades y violencia conyugal. Lima, Perú: Universidad Peruana Cayetano Heredia.

Romero, A. (2010) Intervención en violencia de género. Consideraciones en torno al tratamiento. http:// scielo.isciii.es / scielo.php?script $=$ sci_arttext\&pi$\mathrm{d}=$ S1132-05592010000200010.

Ruíz, P. (2001). Género y masculinidades en subversiones masculinas. 1ra ed. Lima, Perú: Flora Tristán.

Walker, L. (1979). The battered woman. 4th edition USA: Springer Publishing Compay ed.

Yugueros, A. (2014), La violencia contra las mujeres: conceptos y causas. barataria. Revista Castellano-Manchega de Ciencias Sociales [en linea] 2014, (enero-diciembre): [Fecha de consulta: 9 de julio de 2019]. 
Disponible en:<http://www.redalyc.org/articulo. oa?id=322132553010 > ISSN 1575-0825

Zafra, K. (2015). Los centros de emergencia mujer, su intervención frente a los sistemas de género asentados en la sociedad y en la cultura andina en la provincia de SucreAyacucho (Tesis de maestría) Pontificia Universidad Católica del Perú.

Zizek, S. (2009). Sobre la violencia. Seis reflexiones marginales. 1 ra ed. Buenos Aires, Argentina: Paidós. 